ORIGINAL ARTICLE

\title{
Prognostic value of activated Akt expression in oral squamous cell carcinoma
}

\author{
J Lim, J-H Kim, J-Y Paeng, M-J Kim, S-D Hong, J-I Lee, S-P Hong
}

J Clin Pathol 2005;58:1199-1205. doi: 10.1136/icp.2004.024786

See end of article for authors' affiliations ....................

Correspondence to: Dr S-PHong, Department of Oral Pathology, Dental School, Dental Research Institute, Seoul National University, 28-2 Yongondong, Jongno-gu, Seoul 110-744, Korea; zjon0224@snu.ac.kr

Accepted for publication 9 March 2005
Background: Akt is a serine/threonine kinase that plays an important role in tumorigenesis and influences prognosis in several cancers. However, its importance in oral squamous cell carcinomas (OSCC) has not been elucidated.

Aim: To investigate the association between the expression of activated Akt, clinicopathological factors, and E-cadherin, PCNA (proliferating cell nuclear antigen), and VEGF (vascular endothelial growth factor) expression to verify the validity of Akt as a prognostic factor in OSCC.

Methods: Phosphorylated Akt (p-Akt), E-cadherin, PCNA, and VEGF expression were assessed immunohistochemically in 84 OSCCs. The results were analysed in relation to clinicopathological factors. Results: $\mathrm{p}$-Akt was expressed in 29 cases. It was significantly correlated with lymph node metastasis, TNM stage, and E-cadherin expression. Univariate analysis showed that $\mathrm{p}$-Akt expression, E-cadherin expression, PCNA expression, differentiation, tumour size, lymph node metastasis, TNM stage, and recurrence correlated with prognosis. Multivariate analysis showed that $\mathrm{p}$-Akt expression is an independent prognostic factor in patients with OSCC.

Conclusions: This study revealed that Akt activation is a significant prognostic indicator for OSCC and is correlated with E-cadherin expression. The inhibition of Akt is a possible molecular approach to the treatment of OSCC.
O ral cancer is the sixth most common cancer worldwide. The most common type of oral cancer is squamous cell carcinoma, which accounts for almost nine out of 10 oral malignancies. ${ }^{1}$ The prognostic evaluation and decisions on treatment strategy are mainly based on the TNM stage. ${ }^{2}$ Despite progress in treatment modalities over the past few decades, oral cancer still has a poor survival rate, with a high incidence of metastasis. ${ }^{3}{ }^{4}$ Oncogenes, tumour suppressor genes, ${ }^{,-7}$ cell proliferation markers, ${ }^{8}$ angiogenesis, ${ }^{9}$ and cell adhesion molecules ${ }^{10}{ }^{11}$ have been studied as potential tools to predict the prognosis of an individual with oral squamous cell carcinoma (OSCC).

"Despite progress in treatment modalities over the past few decades, oral cancer still has a poor survival rate, with a high incidence of metastasis"

The oncogenic serine/threonine kinase Aktl (also known as $\mathrm{PKB}$ ) is a downstream effector of phosphatidylinositol 3kinase and is frequently activated in human cancer. ${ }^{12}$ The gene for the closely related Akt2 is amplified and overexpressed in ovarian, pancreatic, breast, and follicular thyroid carcinomas. ${ }^{13-17}$ In addition, total Akt kinase activity is increased in non-small cell lung cancer, squamous cell carcinomas of the oral cavity, breast carcinoma, and prostate carcinoma. ${ }^{18-20}$ Akt activation contributes to tumorigenesis.

The main biological consequences of Akt activation that are relevant to cancer cell growth can be classified loosely into three categories: survival, proliferation (increased cell number), and growth (increased cell size). ${ }^{21}$

Akt activation is also associated with enhanced tumour cell invasion. Akt enhances invasiveness of pancreatic carcinoma cells via upregulation of insulin-like growth factor $\mathrm{I}^{22}$ and it increases the secretion of matrix metalloproteinases 2 and 9 in immortalised mammary epithelial cells and ovarian carcinomas. ${ }^{23}{ }^{24}$ Activation of the Akt pathway in cancer cells leads to epithelial-mesenchymal transition and invasion in vivo. Akt induced epithelial-mesenchymal transition involves downregulation of E-cadherin, which appears to result from upregulation of the transcription repressor SNAIL. ${ }^{25}$

Akt has additional effects on tumour induced angiogenesis that are mediated, in part, through hypoxia inducible factor $1 \alpha$ and vascular endothelial growth factor (VEGF). ${ }^{21}$

There are few reports that have examined the relation between activated Akt expression, clinicopathological factors, and Akt related gene expression in OSCC.

The purpose of our study was to clarify the relation between activated Akt expression, clinicopathological factors, and the expression of E-cadherin, proliferating cell nuclear antigen (PCNA), and VEGF. Accordingly, the potential value of Akt as a prognostic indicator of survival was assessed.

\section{MATERIALS AND METHODS}

\section{Patients and tumour samples}

Eighty four patients (62 men and 22 women) with OSCC were examined by immunohistochemistry. All tumours were surgically removed at the department of oral and maxillofacial surgery, Seoul National University Dental Hospital, South Korea, between 1992 and 2001. The age of the patients ranged from 27 to 93 years, with a mean of 59.0 years. Clinical data obtained from patient charts included age, sex, smoking habits, alcohol consumption, TNM stage, and recurrence. Tumours were staged according to the current TNM classification as recommended by the AJCC. ${ }^{26}$ Tumours were re-reviewed by two pathologists to determine the histological grade (well differentiated, moderately differentiated, or poorly differentiated). Survival was calculated from

Abbreviations: LI, labelling index; OSCC, oral squamous cell carcinoma; PBS, phosphate buffered saline; p-Akt, phosphorylated Akt; PCNA, proliferating cell nuclear antigen; VEGF, vascular endothelial growth factor 
Table 1 Summary of the clinicopathological features and p-Akt, E-cadherin, VEGF, and PCNA expression

\begin{tabular}{|c|c|c|c|c|c|c|c|c|c|c|c|c|c|}
\hline Case & Age & Sex & Sm. & Al. & Dif. & TNM & Stage & Rec. & p-AKT & E-cadherin & VEGF & PCNA I & DOF/Status \\
\hline 1 & 41 & $M$ & Yes & Yes & Well & TINOMO & I & & Neg. & Neg. & Neg. & 68 & $56 / \mathrm{L}$ \\
\hline 2 & 66 & $M$ & No & No & Well & T2NOMO & $\|$ & & Pos. & Neg. & Pos. & 50 & $44 / \mathrm{L}$ \\
\hline 3 & 45 & $M$ & No & Yes & Well & $\mathrm{T} 4 \mathrm{~N} 1 \mathrm{MO}$ & IV & & Neg. & Pos. & Pos. & 31 & $44 / \mathrm{L}$ \\
\hline 4 & 67 & $M$ & Yes & No & Well & T4N1MO & IV & & Neg. & Neg. & Neg. & 57 & $7 / D$ \\
\hline 5 & 66 & $\mathrm{~F}$ & No & No & Well & TINOMO & 1 & & Neg. & Pos. & Pos. & 36 & $54 / \mathrm{L}$ \\
\hline 6 & 82 & $\mathrm{~F}$ & No & No & Well & $\mathrm{T} 4 \mathrm{~N} 1 \mathrm{MO}$ & IV & & Pos. & Neg. & Pos. & 35 & $8 / D$ \\
\hline 7 & 58 & $\mathrm{~F}$ & No & No & Well & TINOMO & 1 & & Neg. & Neg. & Neg. & 51 & $52 / \mathrm{L}$ \\
\hline 8 & 60 & $M$ & No & Yes & Well & TINOMO & I & $\mathrm{R}$ & Neg. & Pos. & Neg. & 11 & $41 / \mathrm{L}$ \\
\hline 9 & 55 & $M$ & Yes & Yes & Mod. & TINOMO & 1 & $\mathrm{R}$ & Neg. & Neg. & Neg. & 33 & $68 / L$ \\
\hline 10 & 53 & $M$ & Yes & No & Mod. & TINOMO & 1 & & Neg. & Neg. & Pos. & 40 & $51 / \mathrm{L}$ \\
\hline 11 & 52 & $M$ & Yes & No & Well & T2NOMO & $\|$ & $\mathrm{R}$ & Pos. & Neg. & Pos. & 41 & $22 / D$ \\
\hline 12 & 63 & $M$ & Yes & Yes & Well & $\mathrm{T} 2 \mathrm{~N} 1 \mathrm{MO}$ & IV & & Pos. & Neg. & Pos. & 71 & $18 / D$ \\
\hline 13 & 45 & $M$ & No & Yes & Well & TINOMO & 1 & & Neg. & Pos. & Pos. & 40 & $38 / L$ \\
\hline 14 & 52 & $M$ & No & Yes & Well & TINOMO & 1 & & Neg. & Neg. & Pos. & 76 & $38 / L$ \\
\hline 15 & 57 & $\mathrm{~F}$ & No & No & Well & T4N1M1 & IV & & Neg. & Pos. & Pos. & 39 & $49 / \mathrm{L}$ \\
\hline 16 & 39 & $\mathrm{~F}$ & No & No & Well & T2NOMO & $\|$ & & Pos. & Neg. & Pos. & 53 & $49 / \mathrm{L}$ \\
\hline 17 & 66 & $M$ & Yes & No & Mod. & T4NOMO & IV & & Pos. & Neg. & Pos. & 70 & $48 / \mathrm{L}$ \\
\hline 18 & 52 & $\mathrm{~F}$ & No & No & Well & TINOMO & 1 & & Neg. & Pos. & Pos. & 77 & $34 / \mathrm{L}$ \\
\hline 19 & 52 & $\mathrm{~F}$ & No & No & Poor & T2NOMO & ॥ & & Pos. & Neg. & Pos. & 73 & $5 / D$ \\
\hline 20 & 66 & $\mathrm{~F}$ & No & No & Well & TINOMO & 1 & & Neg. & Pos. & Pos. & 54 & $47 / \mathrm{L}$ \\
\hline 21 & 64 & $M$ & Yes & Yes & Mod. & T2NOMO & $\|$ & $\mathrm{R}$ & Neg. & Neg. & Pos. & 40 & $9 / D$ \\
\hline 22 & 67 & $M$ & Yes & Yes & Mod. & T2NOMO & $\|$ & & Neg. & Neg. & Pos. & 50 & $47 / \mathrm{L}$ \\
\hline 23 & 64 & $M$ & Yes & Yes & Well & T2NOMO & $\|$ & & Neg. & Pos. & Pos. & 45 & $46 / \mathrm{L}$ \\
\hline 24 & 72 & $M$ & No & No & Mod. & T2NOMO & $\|$ & $\mathrm{R}$ & Pos. & Neg. & Pos. & 62 & $24 / D$ \\
\hline 25 & 39 & $M$ & Yes & Yes & Well & T2NOMO & $\|$ & & Neg. & Pos. & Neg. & 62 & $45 / \mathrm{L}$ \\
\hline 26 & 45 & $M$ & Yes & Yes & Well & T2N1MO & IV & & Neg. & Pos. & Pos. & 48 & $45 / \mathrm{L}$ \\
\hline 27 & 69 & $M$ & Yes & Yes & Well & TINOMO & 1 & & Pos. & Neg. & Pos. & 28 & $45 / \mathrm{L}$ \\
\hline 28 & 52 & $\mathrm{~F}$ & No & No & Mod. & T2NOMO & $\|$ & & Neg. & Neg. & Neg. & 70 & $44 / \mathrm{L}$ \\
\hline 29 & 66 & $M$ & No & No & Well & TINOMO & 1 & & Neg. & Pos. & Neg. & 29 & $32 / \mathrm{L}$ \\
\hline 30 & 56 & $M$ & No & Yes & Mod. & T4N1MO & IV & $\mathrm{R}$ & Neg. & Pos. & Neg. & 68 & $42 / \mathrm{L}$ \\
\hline 31 & 64 & $M$ & No & No & Well & T2N1MO & III & $\mathrm{R}$ & Pos. & Neg. & Pos. & 52 & $14 / D$ \\
\hline 32 & 78 & $\mathrm{~F}$ & No & No & Well & T2N1MO & III & $\mathrm{R}$ & Pos. & Neg. & Pos. & 58 & $8 / D$ \\
\hline 33 & 58 & $M$ & Yes & Yes & Mod. & T4N1MO & IV & $\mathrm{R}$ & Pos. & Neg. & Pos. & 69 & $16 / D$ \\
\hline 34 & 76 & $\mathrm{~F}$ & No & No & Well & T4NOMO & IV & $\mathrm{R}$ & Neg. & Pos. & Neg. & 11 & $37 / \mathrm{L}$ \\
\hline $\begin{array}{l}34 \\
35\end{array}$ & 65 & $M$ & No & No & Well & T4N1MO & IV & & Neg. & Pos. & Pos. & 88 & $5 / D$ \\
\hline 36 & 64 & $M$ & No & No & Well & T2NOMO & $\|$ & & Neg. & Pos. & Pos. & 80 & $32 / \mathrm{L}$ \\
\hline 37 & 65 & $M$ & Yes & Yes & Well & T3N1MO & III & $\mathrm{R}$ & Neg. & Neg. & Pos. & 72 & $4 / D$ \\
\hline 38 & 60 & $M$ & Yes & Yes & Poor & T4NOMO & IV & $\mathrm{R}$ & Neg. & Pos. & Neg. & 71 & $9 / D$ \\
\hline 39 & 66 & $M$ & Yes & Yes & Well & TIN1MO & IV & $\mathrm{R}$ & Pos. & Neg. & Pos. & 18 & $7 / D$ \\
\hline 40 & 68 & $M$ & No & No & Mod. & T4NIMO & IV & & Pos. & Pos. & Pos. & 77 & $30 / \mathrm{L}$ \\
\hline 41 & 55 & $M$ & No & No & Mod. & $\mathrm{T} 4 \mathrm{~N} 1 \mathrm{MO}$ & IV & $\mathrm{R}$ & Pos. & Neg. & Pos. & 67 & $9 / D$ \\
\hline 42 & 67 & $M$ & Yes & Yes & Well & $\mathrm{T} 4 \mathrm{~N} 1 \mathrm{MO}$ & IV & & Pos. & Neg. & Pos. & 95 & $13 / D$ \\
\hline 43 & 27 & $M$ & Yes & Yes & Well & TINOMO & 1 & & Neg. & Neg. & Neg. & 66 & $28 / L$ \\
\hline 44 & 57 & $M$ & Yes & Yes & Well & TINOMO & i & & Neg. & Pos. & Pos. & 49 & $32 / L$ \\
\hline 45 & 60 & $M$ & Yes & Yes & Well & TINIMI & III & & Neg. & Pos. & Pos. & 57 & $28 / L$ \\
\hline 46 & 72 & $\mathrm{~F}$ & No & No & Well & TANOMO & IV & & Neg. & Pos. & Neg. & 69 & $27 / L$ \\
\hline 47 & 93 & $M$ & No & No & Poor & T2NOMO & $\|$ & & Neg. & Pos. & Pos. & 56 & $26 / L$ \\
\hline 48 & 67 & $\mathrm{~F}$ & No & No & Well & T2N1MO & III & $\mathrm{R}$ & Pos. & Neg. & Neg. & 67 & $27 / L$ \\
\hline 49 & 49 & $M$ & No & No & Well & TINOMO & I & & Neg. & Pos. & Neg. & 76 & $26 / L$ \\
\hline 50 & 82 & $M$ & No & No & Mod. & T4NOMO & IV & & Neg. & Pos. & Pos. & 57 & $25 / \mathrm{L}$ \\
\hline 51 & 66 & $\mathrm{~F}$ & No & No & Well & TINOMO & I & & Neg. & Neg. & Neg. & 42 & $40 / \mathrm{L}$ \\
\hline 52 & 58 & $M$ & Yes & Yes & Well & TANOMO & IV & & Neg. & Pos. & Pos. & 68 & $24 / L$ \\
\hline 53 & 70 & $M$ & No & No & Well & T2NOMO & $\|$ & $\mathrm{R}$ & Neq. & Pos. & Pos. & 76 & $2 / D$ \\
\hline 54 & 53 & $\mathrm{~F}$ & No & No & Well & TINIMO & III & $\mathrm{R}$ & Neg. & Neg. & Pos. & 51 & $16 / \mathrm{L}$ \\
\hline 55 & 54 & $\mathrm{~F}$ & No & No & Well & T2NOMO & $\|$ & $\mathrm{R}$ & Neg. & Neg. & Pos. & 59 & $30 / \mathrm{L}$ \\
\hline 56 & 45 & $M$ & Yes & Yes & Mod. & T4N1MI & IV & $\mathrm{R}$ & Neg. & Neg. & Pos. & 39 & $26 / L$ \\
\hline 57 & 28 & $\mathrm{~F}$ & No & No & Well & TINOMO & 1 & & Neg. & Neg. & Pos. & 54 & $75 / \mathrm{L}$ \\
\hline 58 & 34 & $M$ & No & No & Well & T4N1MO & IV & & Pos. & Neg. & Pos. & 70 & $104 / \mathrm{L}$ \\
\hline 59 & 58 & $M$ & Yes & Yes & Mod. & T4NOMO & IV & $R$ & Pos. & Neg. & Pos. & 51 & $16 / D$ \\
\hline 60 & 71 & $M$ & Yes & Yes & Well & TINOMO & 1 & & Neg. & Neg. & Pos. & 82 & $13 / D$ \\
\hline 61 & 46 & $M$ & No & No & Well & T4NOMO & IV & $\mathrm{R}$ & Neg. & $\begin{array}{l}\text { Neg. } \\
\text { Pos. }\end{array}$ & Neg. & $\begin{array}{l}02 \\
31\end{array}$ & $8 / D$ \\
\hline 62 & 65 & $M$ & Yes & Yes & Well & T2NOMO & II & & Neg. & Pos. & Neg. & 66 & $80 / \mathrm{L}$ \\
\hline 63 & 55 & $M$ & No & No & Well & TANOMO & IV & $\mathrm{R}$ & Pos. & Neg. & Pos. & 62 & $92 / \mathrm{L}$ \\
\hline 64 & 39 & $\mathrm{~F}$ & Yes & No & Well & T4N1MO & IV & $\mathrm{R}$ & Neg. & Neg. & Pos. & 42 & $26 / D$ \\
\hline 65 & 46 & $M$ & Yes & Yes & Well & TINOMO & 1 & & Pos. & Pos. & Neg. & 39 & $70 / \mathrm{L}$ \\
\hline 66 & 84 & $M$ & Yes & Yes & Mod. & $\mathrm{T} 4 \mathrm{~N} 1 \mathrm{MO}$ & IV & & Pos. & Neg. & Neg. & 81 & $6 / D$ \\
\hline 67 & 55 & $\mathrm{~F}$ & No & No & Well & TINOMO & 1 & $\mathrm{R}$ & Neg. & Pos. & Pos. & 81 & $134 / \mathrm{L}$ \\
\hline 68 & 63 & $\mathrm{~F}$ & No & No & Mod. & T4N1MO & IV & & Neg. & Pos. & Pos. & 31 & $17 / D$ \\
\hline 69 & 58 & $M$ & Yes & Yes & Mod. & T4NOMO & IV & & Neg. & Pos. & Pos. & 71 & $27 / D$ \\
\hline 70 & 57 & $M$ & Yes & Yes & Well & T4N1MO & IV & $\mathrm{R}$ & Pos. & Neg. & Pos. & 68 & $13 / D$ \\
\hline 71 & 62 & $M$ & Yes & Yes & Well & TINOMO & 1 & & Neg. & Pos. & Neg. & 68 & $66 / \mathrm{L}$ \\
\hline 72 & 55 & $\mathrm{~F}$ & No & No & Well & T4NOMO & IV & $\mathrm{R}$ & Pos. & Pos. & Pos. & 71 & $14 / D$ \\
\hline 73 & 69 & $M$ & Yes & Yes & Well & TINOMO & I & $\mathrm{R}$ & Neg. & Pos. & Pos. & 74 & $66 / \mathrm{L}$ \\
\hline 74 & 50 & $M$ & Yes & Yes & Well & T4NOMO & IV & & Neq. & Pos. & Neg. & 7 & $62 / \mathrm{L}$ \\
\hline 75 & 63 & $\mathrm{~F}$ & No & No & Well & TINOMO & 1 & & Neg. & Pos. & Pos. & 59 & $25 / D$ \\
\hline 76 & 64 & $M$ & Yes & Yes & Well & T2NOMO & II & & Pos. & Neg. & Pos. & 77 & $5 / D$ \\
\hline 77 & 73 & $M$ & Yes & Yes & Well & T2NOMO & $\|$ & $\mathrm{R}$ & Neg. & Pos. & Pos. & 62 & $38 / D$ \\
\hline 78 & 45 & $M$ & No & No & Well & T4N1MI & IV & $\mathrm{R}$ & Pos. & Neg. & Neg. & 57 & $62 / \mathrm{L}$ \\
\hline 79 & 59 & $M$ & Yes & Yes & Mod. & T4NOMO & IV & & Pos. & Pos. & Neg. & 55 & $8 / D$ \\
\hline 80 & 55 & $M$ & No & Yes & Well & TINOMO & I & & Neg. & Pos. & Neg. & 68 & $61 / \mathrm{L}$ \\
\hline 81 & 58 & $M$ & Yes & Yes & Poor & $\mathrm{T} 4 \mathrm{~N} 1 \mathrm{MO}$ & IV & & Pos. & Neg. & Neg. & 93 & $6 / D$ \\
\hline
\end{tabular}


Table 1 Continued

\begin{tabular}{|c|c|c|c|c|c|c|c|c|c|c|c|c|c|}
\hline Case & Age & Sex & Sm. & Al. & Dif. & TNM & Stage & Rec. & p-AKT & E-cadherin & VEGF & PCNA I & DOF/Status \\
\hline 82 & 56 & $M$ & No & No & Well & T2N1M0 & III & & Neg. & Pos. & Pos. & 39 & $60 / L$ \\
\hline 83 & 59 & $M$ & Yes & No & Mod. & T4N1MO & IV & & Neg. & Neg. & Neg. & 50 & $20 / D$ \\
\hline 84 & 63 & $M$ & Yes & No & Well & TINOMO & I & & Pos. & Neg. & Pos. & 81 & $58 / \mathrm{L}$ \\
\hline
\end{tabular}

Al., alcohol drinking habit; D, dead; Dif., differentiation; DOF, duration of follow up; F, female; L, living; M, male; Mod., moderate; Neg., negative; $\mathrm{p}$-Akt, phosphorylated Akt; PCNA I, PCNA labelling index; Pos., positive; R, recurred; Rec., recurrence; Sm., smoking habit; VEGF, vascular endothelial growth factor.

the date of diagnosis until the date of death or last follow up (table 1).

\section{Immunohistochemistry}

Immunohistochemical staining was performed using the streptavidin-biotin-peroxidase complex method. Sections ( $4 \mu \mathrm{m}$ thick) were cut from each paraffin wax block, dewaxed, and incubated for 15 minutes in a methanol solution containing $3 \% \mathrm{H}_{2} \mathrm{O}_{2}$ to block endogenous peroxidase activity. For phosphorylated Akt (p-Akt), E-cadherin, and VEGF staining, the slides were placed in $0.01 \mathrm{M}$ citrate buffer ( $\mathrm{pH}$ 6.0) and heated in a $500 \mathrm{~W}$ microwave oven for two five minute periods. After washing with phosphate buffered saline (PBS), sections were incubated in 10\% normal rabbit serum for 30 minutes to reduce non-specific antibody binding. The primary antibodies used were: monoclonal rabbit antihuman p-Akt (Ser 473; Cell Signaling Technology, Beverley, Massachusetts, USA) at a dilution of $1 / 50$; monoclonal mouse antihuman VEGF (clone G153-694; Pharmingen, San Diego, California, USA) at a dilution of $\mathrm{l} /$ 400; monoclonal mouse antihuman E-cadherin (G-10; Santa Cruz Biotechnology, Santa Cruz, California, USA) at a dilution of 1/200; and monoclonal mouse antihuman PCNA (P-10; Dako, Glostrup, Denmark) at a dilution of 1/100. All sections were incubated for one hour at room temperature, except for the Akt sections, which were incubated overnight at $4^{\circ} \mathrm{C}$. After being washed with PBS, sections were incubated with biotinylated goat antirabbit IgG for 30 minutes. They were then washed three times with PBS, treated with streptavidin-peroxidase reagent for 30 minutes, and rewashed with PBS three times. The reactions were visualised with diaminobenzidine (Dako) as chromogen and sections were counterstained with Mayer's haematoxylin. Normal mouse and rabbit IgG were substituted for each primary antibody as negative controls.

\section{Evaluation of immunohistochemical results}

The cutoff points were based on the distribution of staining results or the results of other studies in the literature, because clear biological criteria are not available. For p-Akt the cutoff point was $0-20 \% v>20 \%{ }^{27}$ For E-cadherin, expression was defined as positive when at least $50 \%$ of the cells showed membrane staining. ${ }^{28}$ For VEGF, the cutoff point was $20 \% .{ }^{29}$ For PCNA, nuclei from over 1000 tumour cells were counted in the five to eight random fields chosen for each sample and the count was expressed as the percentage of PCNA positive cells (PCNA labelling index; LI).

The slides were assessed by consensus between two investigators who had no prior knowledge of the corresponding clinicopathological data.

\section{Statistical analysis}

Relations between p-Akt, E-cadherin, and VEGF and the various clinicopathological factors were examined using the $\chi^{2}$ test. The mean value and SD of PCNA LIs were calculated and compared with clinicopathological factors using the Student's $t$ test.

Table 2 Correlation between p-Akt, E-cadherin, PCNA, and VEGF expression and clinicopathological features

\begin{tabular}{|c|c|c|c|c|c|}
\hline Variables & $\mathrm{N}$ & p-AKT+ n (\%) & E-cad+ n (\%) & Mean (SD) PCNA LI & VEGF+ n (\%) \\
\hline \multicolumn{6}{|l|}{ Age } \\
\hline$<60$ & 42 & $14(33.3 \%)$ & $19(45.2 \%)$ & $56.5(17.2)$ & $27(64.3 \%)$ \\
\hline$\geqslant 60$ & 42 & $15(35.7 \%)$ & $21(50.0 \%)$ & $57.5(20.6)$ & $30(71.4 \%)$ \\
\hline \multicolumn{6}{|l|}{ Sex } \\
\hline Male & 62 & $23(37.1 \%)$ & $30(48.4 \%)$ & 58.1 (19.3) & $41(66.1 \%)$ \\
\hline Female & 22 & $6(27.3 \%)$ & $10(45.5 \%)$ & 53.7 (17.3) & $16(72.7 \%)$ \\
\hline \multicolumn{6}{|l|}{ Smoking } \\
\hline Yes & 40 & $15(37.5 \%)$ & $15(37.5 \%)$ & 58.1 (19.3) & $26(65.0 \%)$ \\
\hline No & 44 & $14(31.8 \%)$ & $25(56.8 \%)$ & $56.0(18.5)$ & $31(70.5 \%)$ \\
\hline \multicolumn{6}{|l|}{ Alcohol } \\
\hline$<1 \mathrm{~B} / \mathrm{w}$ & 39 & $12(30.8 \%)$ & $20(51.3 \%)$ & $57.4(21.0)$ & $24(61.5 \%)$ \\
\hline$\geqslant 1 \mathrm{~B} / \mathrm{w}$ & 45 & $17(37.8 \%)$ & $20(44.4 \%)$ & $56.7(17.0)$ & $33(73.3 \%)$ \\
\hline \multicolumn{6}{|l|}{ Differentiation } \\
\hline Well & 61 & $19(31.1 \%)$ & $32(52.5 \%)$ & $56.0(19.8)$ & 42 (68.9\%) \\
\hline Moderate/Poor & 23 & $10(43.5 \%)$ & $8(34.8 \%)$ & 59.7 (16.2) & $15(65.2 \%)$ \\
\hline \multicolumn{6}{|l|}{ Tumour size } \\
\hline $\mathrm{T} 1 / \mathrm{T} 2$ & 51 & $14(27.5 \%)$ & $24(47.1 \%)$ & $56.2(17.1)$ & $36(70.6 \%)$ \\
\hline $\mathrm{T} 3 / \mathrm{T} 4$ & 33 & $15(45.5 \%)$ & $16(48.5 \%)$ & $58.3(21.4)$ & $21(63.6 \%)$ \\
\hline \multicolumn{6}{|l|}{ LN metastasis } \\
\hline Positive & 29 & $15(51.7 \%)^{*}$ & $9(31.0 \%)^{*}$ & $58.2(19.4)$ & $22(75.9 \%)$ \\
\hline Negative & 55 & $14(25.5 \%)^{*}$ & $31(56.4 \%)^{*}$ & $56.3(18.6)$ & 35 (63.6\%) \\
\hline \multicolumn{6}{|l|}{ Clinical stage } \\
\hline I/II & 42 & $9(21.4 \%)$ * & $21(45.2 \%)$ & $57.2(17.4)$ & $28(66.7 \%)$ \\
\hline III/IV & 42 & $20(47.6 \%)^{*}$ & $19(50.0 \%)$ & $56.8(20.4)$ & $29(69.0 \%)$ \\
\hline \multicolumn{6}{|l|}{ Recurrence } \\
\hline Yes & 29 & $13(44.8 \%)$ & 10 (34.5\%) & $53.9(19.4)$ & $21(72.4 \%)$ \\
\hline No & 55 & $16(29.1 \%)$ & $30(54.5 \%)$ & $58.6(18.5)$ & $36(65.5 \%)$ \\
\hline
\end{tabular}



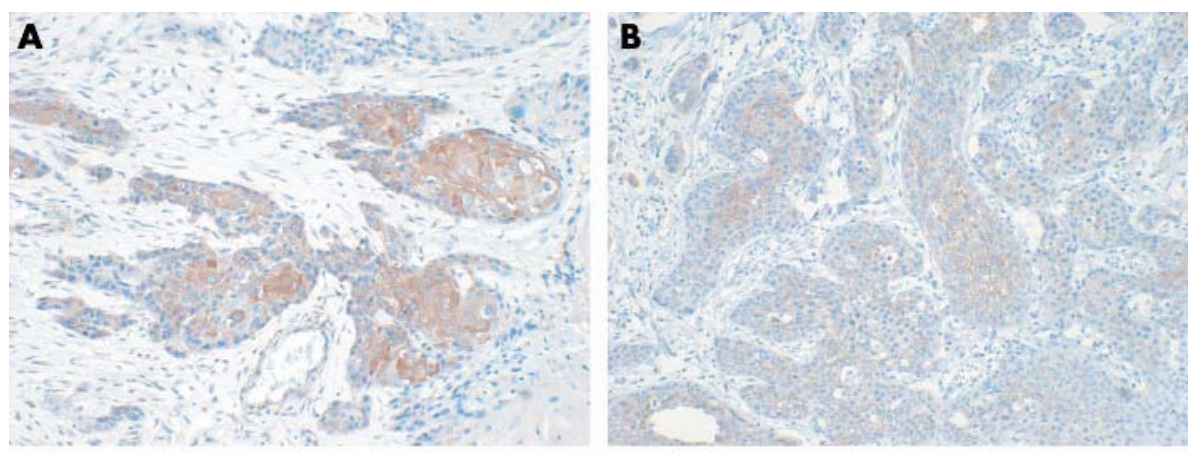

Figure 1 Immunohistochemical staining in oral squamous cell carcinoma. (A) Positive expression of phosphorylated Akt (original magnification, $\times 200)$; (B) positive expression of $\mathrm{E}$-cadherin (original magnification, $\times 200$ ); (C) high expression of PCNA (original magnification, $\times 100)$; (D) positive expression of VEGF (original magnification, $\times 200$ ).
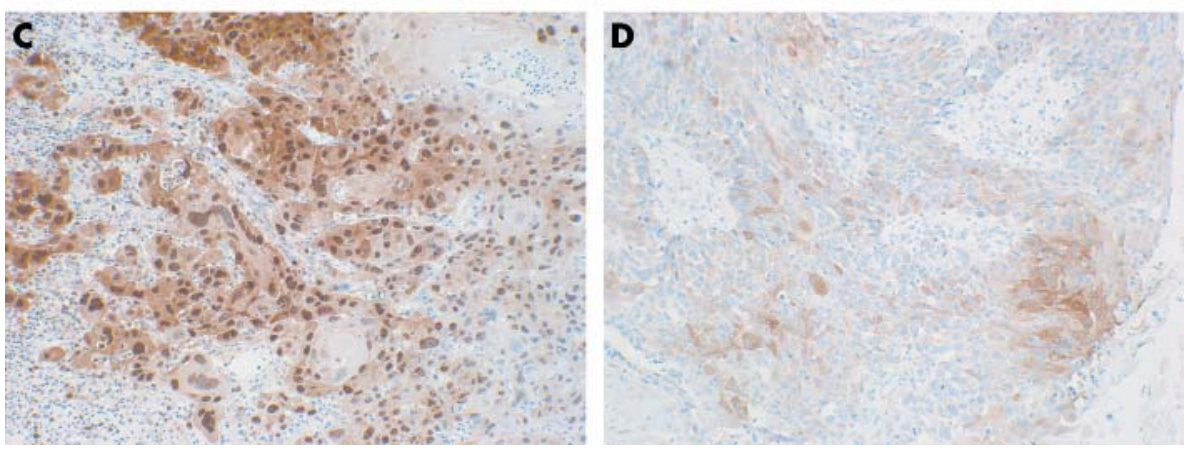

Survival curves were calculated using the Kaplan-Meier method and analysed using the log rank test. The expression of PCNA was classified as high at $\geqslant 60 \%$ and low at $<60 \%$ for the Kaplan-Meier method. Deaths caused by OSCC were considered as outcomes and all deaths from other causes were censored. The roles of each identified prognostic factor (by univariate analysis) and combined effects (by multivariate analysis) were explored using the Cox proportional hazards survival analysis model. In the univariate analysis, the hazards ratio and its 95\% confidence interval were calculated for each variable. Forward and backward stepwise procedures were used to identify the combination of factors that was important in the prediction of prognosis. All statistical analyses were considered significant when the $\mathrm{p}$ value was less than 0.05 . Statistical analyses were performed using SPSS version 11.5.

\section{RESULTS}

Correlation between p-Akt, E-cadherin, PCNA, and VEGF expression and clinicopathological factors

Table 2 shows the association of several clinicopathological factors with p-Akt, E-cadherin, PCNA, and VEGF expression. P-Akt expression was positive in 29 cases (fig lA). p-Akt staining significantly correlated with lymph node metastasis and clinical stage $(\mathrm{p}<0.05)$. Patients with a smoking habit, poor differentiation, large tumour size, and recurrence tended to show higher p-Akt expression, but the result was not significant.

E-cadherin was expressed in 40 cases and correlated with lymph node metastasis $(\mathrm{p}<0.05)$. The mean PCNA LI was 57.0 and VEGF was expressed in 57 cases. There was no significant correlation between PCNA and VEGF expression and clinicopathological factors.

\section{Correlation between $\mathrm{p}$-Akt expression and the expression of E-cadherin, VEGF, and PCNA}

Table 3 shows that p-AKT expression was significantly higher in cases with high expression of E-cadherin than in those with low expression $(p=0.001)$. Cases with high VEGF or PCNA expression had higher p-Akt expression, but this was not significant $(\mathrm{p}=0.143$ and $\mathrm{p}=0.091$, respectively).

\section{Survival analysis}

Univariate Cox proportional hazards survival analysis of 84 OSCCs showed that the following factors indicated a worse prognosis (table 4): poor differentiation $(\mathrm{p}=0.039)$, large tumour size $(p=0.003)$, high clinical stage $(p=0.0002)$, positive lymph node metastasis $(\mathrm{p}=0.003)$, recurrent

Table 3 Correlation between expression of $\mathrm{p}$-Akt and E-cadherin, PCNA, and VEGF expression

\begin{tabular}{|c|c|c|c|c|}
\hline \multirow[b]{2}{*}{ Variables } & \multirow[b]{2}{*}{$\mathbf{N}$} & \multicolumn{3}{|l|}{ p-Akt } \\
\hline & & Negative & Positive & p Value* \\
\hline \multicolumn{5}{|l|}{ E-cadherin expression } \\
\hline Negative & 44 & $19(22.6 \%)$ & $25(29.8 \%)$ & 0.001 \\
\hline Positive & 40 & $36(42.9 \%)$ & $4(4.8 \%)$ & \\
\hline Mean (SD) PCNA LI & & $54.5(18.9)$ & $61.8(18.1)$ & 0.091 \\
\hline \multicolumn{5}{|l|}{ VEGF expression } \\
\hline Negative & 27 & $21(25.0 \%)$ & $6(7.1 \%)$ & 0.143 \\
\hline Positive & 57 & $34(40.5 \%)$ & $23(27.4 \%)$ & \\
\hline
\end{tabular}

${ }^{*}$ Chi square test.

p-Akt, phosphorylated Akt; PCNA LI, proliferating cell nuclear antigen labelling index; VEGF, vascular endothelial growth factor. 
Table 4 Univariate analysis of survival in 84 patients with OSCC according to the Cox proportional hazards model

\begin{tabular}{llll}
\hline Variables & Hazards ratio & 95\% Cl & p Value \\
\hline Age ( $\leqslant 60 />60)$ & 1.954 & 0.954 to 3.999 & 0.067 \\
Sex (M/F) & 0.732 & 0.317 to 1.694 & 0.3467 \\
Smoking (yes/no) & 2.030 & 0.992 to 4.156 & 0.053 \\
Alcohol (<1 B/w/ $\geqslant 1 \mathrm{~B} / \mathrm{w}$ ) & 1.192 & 0.596 to 2.385 & 0.619 \\
Differentiation (well/moderate, poor) & 2.106 & 1.037 to 4.275 & 0.039 \\
Tumour size (T1, T2/T3, T4) & 2.899 & 1.426 to 5.895 & 0.003 \\
LN metastasis (positive/negative) & 2.875 & 1.429 to 5.784 & 0.003 \\
Clinical stage (I, II/III,IV) & 3.383 & 1.557 to 7.352 & 0.002 \\
Recurrence (yes/no) & 2.595 & 1.291 to 5.214 & 0.007 \\
p-AKT expression (+/-) & 3.219 & 1.594 to 6.505 & 0.001 \\
E-cadherin expression (+/-) & 0.414 & 0.196 to 0.875 & 0.021 \\
VEGF expression (+/-) & 1.805 & 0.780 to 4.176 & 0.168 \\
PCNA LI & 1.022 & 1.000 to 1.044 \\
\hline
\end{tabular}

$1 \mathrm{~B} / \mathrm{w}, 1$ bottle (360 ml; $25 \%$ alcohol)/week; Cl, confidence interval; F, female; LN, lymph node; $\mathrm{M}$, male; OSCC, oral squamous cell carcinoma; $\mathrm{p}-\mathrm{Akt}$, phosphorylated Akt; PCNA LI, proliferating cell nuclear antigen labelling index; VEGF, vascular endothelial growth factor.

disease $(p=0.007)$, high $p$-Akt expression $(p=0.001)$, low E-cadherin expression $(\mathrm{p}=0.021)$, and high PCNA LI $(\mathrm{p}=0.049)$. Figure $2 \mathrm{~A}-\mathrm{F}$ shows the survival curves calculated by the Kaplan-Meier method and analysed using the log rank test. They show that the survival of patients with high p-Akt expression was significantly worse than that of those with low $\mathrm{p}$-Akt expression $(\mathrm{p}=0.0005)$. Survival was also associated significantly with p-Akt expression in $\mathrm{Tl}$ and
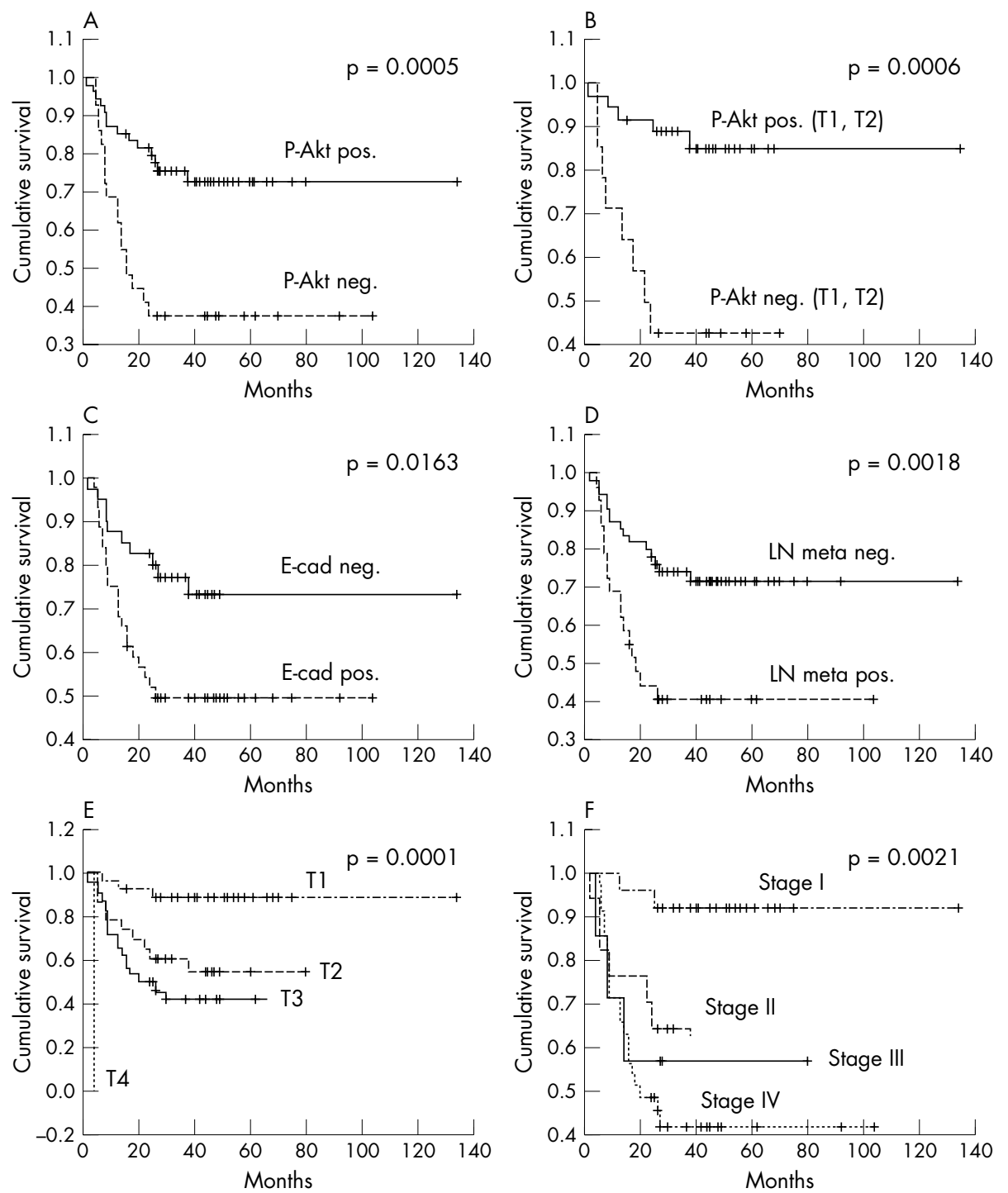

Figure 2 Survival curves of patients with oral squamous cell carcinoma according to (A) phosphorylated Akt (p-Akt) expression, (B) p-Akt expression in T1 and T2 tumours, (C) E-cadherin expression, (D) lymph node (LN) metastasis, (E) tumour size, and (F) clinical stage (Kaplan-Meier method). 
Table 5 Multivariate analysis of survival of 84 patients with OSCC according to the Cox proportional hazards model

\begin{tabular}{llll}
\hline Variables & Hazards ratio & $95 \% \mathrm{Cl}$ & $\mathrm{p}$ Value \\
\hline p-AkT expression & 2.513 & 1.215 to 5.195 & 0.013 \\
Clinical stage (I, II/III,IV) & 2.683 & 1.203 to 5.983 & 0.016 \\
\hline Cl, confidence interval; OSCC, oral squamous cell carcinoma; p-Akt, phosphorylated Akt. & & \\
\hline
\end{tabular}

T2 tumours $(\mathrm{p}=0.0006)$. Multivariate Cox proportional hazards survival analysis revealed that pAkt expression and clinical stage were independent prognostic factors (table 5).

\section{DISCUSSION}

To establish appropriate therapeutic modalities for OSCC, an accurate assessment of the factors affecting tumour progression and patient prognosis is crucial. Although the conventional TNM staging system is useful for OSCC classification, the outcome is poor for patients even in the low stage ( $\mathrm{I}$ and II) groups. Therefore, several molecular markers used for OSCC classification have been investigated, but none showed great value in predicting patient prognosis.

Akt is a central player in the signal transduction pathways activated in response to growth factors or insulin, and is thought to contribute to several cellular functions including cell growth, proliferation, apoptosis, invasion, and angiogenesis. Recently, several important publications have described novel mechanisms of regulating Akt. Alteration of Akt expression and activity is associated with several human cancers including glioblastoma, and ovarian, breast, pancreatic, and lung cancers. ${ }^{21}$

"Phosphorylated Akt expression correlated with lymph node metastasis, the clinical stage of which remains a significant prognostic variable in oral squamous cell carcinoma"

In our study, we used immunohistochemistry to analyse pAkt and Akt related biological factors known to be involved in tumour progression, such as E-cadherin (associated with cancer invasion), VEGF (tumour angiogenesis), and PCNA (marker of tumour proliferative activity).

The reported incidence of p-Akt expression varied from $26 \%$ in prostate cancer $^{27}$ to $66 \%$ in both melanomas ${ }^{30}$ and head and neck squamous cell carcinomas. ${ }^{31}$ We found p-Akt expression in $34.5 \%$ of OSCCs. However, our threshold for positive expression was $20 \%$, higher than the $10 \%$ used in Gupta's study. ${ }^{31}$ If Gupta et al had used our $20 \%$ threshold, they would have found p-Akt expression in $23.7 \%$ of their cases, which is similar to our result.

p-Akt expression correlated with lymph node metastasis, the clinical stage of which remains a significant prognostic variable in OSCC. Gupta et al reported that p-Akt staining was not associated with $\mathrm{T}$ stage, $\mathrm{N}$ stage, or differentiation of disease. However, the number of cases in their study (38) was

\section{Take home messages}

- Activated Akt serine/threonine kinase (p-Akt) is a significant prognostic indicator for oral squamous cell carcinoma (OSCC)

- $p$-Akt is inversely associated with E-cadherin expression in OSCC

- The inhibition of Akt is a possible molecular approach to the treatment of OSCC too small to carry out meaningful multivariate analysis. In pancreatic cancers, Schlieman et al showed that p-Akt expression correlated with higher histological tumour grade. ${ }^{32}$ Because reports on the relations between p-Akt expression and clinicopathological factors are rare, an additional larger scale study would be needed to elucidate this association.

E-cadherin expression is closely related to lymph node metastasis. Several reports have shown that E-cadherin expression is significantly correlated with lymph node metastasis in OSCC. ${ }^{33} 34$

There was no significant correlation between VEGF and PCNA expression and the clinicopathological factors.

Our study suggests a significant inverse correlation between p-Akt and E-cadherin expression in OSCC. This is the first study to demonstrate such an association. Akt activation represses E-cadherin gene transcription by upregulation of the transcription repressors SNAIL and SIP1.25

In our study, univariate and multivariate survival analysis showed that p-Akt and clinical stage were independent prognostic factors in OSCC. The multiple activities of Akt, such as enhancement of proliferation, growth, antiapoptosis, invasiveness, and angiogenesis, endow OSCC with microinvasiveness at the resected margin and promote the invasion and recurrence of cancer. Thus, high p-Akt expression in a patient with OSCC would warrant a more radical mode of treatment.

In conclusion, our study revealed that Akt activation is a significant prognostic indicator for OSCC and may provide a new method of treatment of OSCC. The inhibition of Akt is a possible molecular approach to the treatment of OSCC.

\section{ACKNOWLEDGEMENTS}

This study was supported by the international collaboration research grant 01-2003-000-00192-0 from the Korea Science and Engineering Foundation (KOSEF).

\section{Authors' affiliations}

J Lim, S-D Hong, J-I Lee, S-P Hong, Department of Oral Pathology, Dental School, Dental Research Institute, Seoul National University, 28-2 Yongon-dong, Jongno-gu, Seoul 110-744, Korea

J-H Kim, Department of Dentistry, Pundang Jesaeng Hospital, Pundanggu, Kyounggi-do 463-774, Korea

J-Y Paeng, M-J Kim, Department of Oral and Maxillofacial Surgery, Dental School, Seoul National University

\section{REFERENCES}

1 Silverman SJ. Oral cancer, 4th ed. Atlanta: American Cancer Society, 1998.

2 Sobin LHWC. TNM classification of malignant tumors, 5th ed. New York: Wiley-Liss UICC, 1997.

3 Houck JRMJ. Management of cervical lymph nodes in squamous carcinomas of the head and neck. Semin Surg Oncol 1995;11:228-39.

4 Tankere F, Camproux A, Barry B, et al. Prognostic value of lymph node involvement in oral cancers: a study of 137 cases. Laryngoscope 2000; 110:2061-5.

5 Piattelli A, Rubini C, Fioroni $M$, et al. Prevalence of $\mathrm{p} 53$, bcl-2, and Ki-67 immunoreactivity and of apoptosis in normal oral epithelium and in premalignant and malignant lesions of the oral cavity. J Oral Maxillofac Surg 2002;60:532-40.

6 Shintani S, Yoshihama Y, Emilio AR, et al. Overexpression of p53 is an early event in the tumorigenesis of oral squamous cell carcinomas. Anticancer Res 1995; 15:305-8.

7 Girod SC, Pfeiffer P, Ries J, et al. Proliferative activity and loss of function of tumour suppressor genes as "biomarkers" in diagnosis and prognosis of 
benign and preneoplastic oral lesions and oral squamous cell carcinoma. Br J Oral Maxillofac Surg 1998;36:252-60

8 Matsumoto M, Komiyama K, Okaue M, et al. Predicting tumor metastasis in patients with oral cancer by means of the proliferation marker Ki67. J Oral Sci 1999:41:53-6.

9 Smith BD, Smith GL, Carter D, et al. Prognostic significance of vascular endothelial growth factor protein levels in oral and oropharyngeal squamous cell carcinoma. J Clin Oncol 2000;18:2046-52.

10 Bagutti C, Speight PM, Watt FM. Comparison of integrin, cadherin, and catenin expression in squamous cell carcinomas of the oral cavity. J Pathol 1998; 186:8-16

11 Carinci F, Stabellini G, Calvitti M, et al. CD44 as prognostic factor in oral and oropharyngeal squamous cell carcinoma. J Craniofac Surg 2002;13:85-9.

12 Testa JR, Bellacosa A. AKT plays a central role in tumorigenesis. Proc Natl Acad Sci U S A 2001;98:10983-5.

13 Cheng JQ, Godwin AK, Bellacosa A, et al. AKT2, a putative oncogene encoding a member of a subfamily of protein-serine/threonine kinases, is amplified in human ovarian carcinomas. Proc Natl Acad Sci U S A 1992:89:9267-71.

14 Bellacosa A, de Feo D, Godwin AK, et al. Molecular alterations of the AKT2 oncogene in ovarian and breast carcinomas. Int J Cancer 1995;64:280-5.

15 Cheng JQ, Ruggeri B, Klein WM, et al. Amplification of AKT2 in human pancreatic cells and inhibition of AKT2 expression and tumorigenicity by antisense RNA. Proc Natl Acad Sci U S A 1996:93:3636-41.

16 Ringel MD, Hayre N, Saito J, et al. Overexpression and overactivation of Akt in thyroid carcinoma. Cancer Res 2001;61:6105-11.

17 Yuan ZQ, Sun M, Feldman RI, et al. Frequent activation of AKT2 and induction of apoptosis by inhibition of phosphoinositide-3-OH kinase/Akt pathway in human ovarian cancer. Oncogene 2000;19:2324-30.

18 Nakayama $H$, Ikebe T, Beppu $M$, et al. High expression levels of nuclear factor kappaB, IkappaB kinase alpha and Akt kinase in squamous cell carcinoma of the oral cavity. Cancer 2001;92:3037-44.

19 Sun $\mathrm{M}$, Wang G, Paciga JE, et al. AKTI/PKBalpha kinase is frequently elevated in human cancers and its constitutive activation is required for oncogenic transformation in NIH3T3 cells. Am J Pathol 2001;159:431-7.

20 Brognard J, Clark AS, Ni Y, et al. Akt/protein kinase B is constitutively active in non-small cell lung cancer cells and promotes cellular survival and resistance to chemotherapy and radiation. Cancer Res 2001:61:3986-97.

21 Vivanco I, Sawyers CL. The phosphatidylinositol 3-kinase AKT pathway in human cancer. Nat Rev Cancer 2002;2:489-501.
22 Tanno S, Tanno S, Mitsuuchi Y, et al. AKT activation up-regulates insulin-like growth factor I receptor expression and promotes invasiveness of human pancreatic cancer cells. Cancer Res 2001;61:589-93.

23 Park BK, Zeng X, Glazer RI. Akt1 induces extracellular matrix invasion and matrix metalloproteinase-2 activity in mouse mammary epithelial cells. Cancer Res 2001;61:7647-53.

24 Thant AA, Nawa A, Kikkawa F, et al. Fibronectin activates matrix metalloproteinase-9 secretion via the MEK 1-MAPK and the PI3K-Akt pathways in ovarian cancer cells. Clin Exp Metastasis 2000;18:423-8.

25 Grille SJ, Bellacosa A, Upson J, et al. The protein kinase Akt induces epithelial mesenchymal transition and promotes enhanced motility and invasiveness of squamous cell carcinoma lines. Cancer Res 2003;63:2172-8.

26 Frederick L, Greene DLP, Fleming ID, et al. AJCC cancer staging manual, 6th ed. Chicago: Springer, 2002.

27 Malik SN, Brattain M, Ghosh PM, et al. Immunohistochemical demonstration of phospho-Akt in high Gleason grade prostate cancer. Clin Cancer Res 2002;8:1168-71.

28 Lim SC, Zhang S, Ishii G, et al. Predictive markers for late cervical metastasis in stage I and II invasive squamous cell carcinoma of the oral tongue. Clin Cancer Res 2004;10(1 Pt 1):166-72.

29 Fukuiwa T, Takebayashi Y, Akiba S, et al. Expression of thymidine phosphorylase and vascular endothelial cell growth factor in human head and neck squamous cell carcinoma and their different characteristics. Cancer 1999;85:960-9.

30 Dhawan $P$, Singh $A B$, Ellis $D L$, et al. Constitutive activation of $A k t /$ protein kinase $B$ in melanoma leads to up-regulation of nuclear factor-kappaB and tumor progression. Cancer Res 2002;62:7335-42.

31 Gupta AK, McKenna WG, Weber CN, et al. Local recurrence in head and neck cancer: relationship to radiation resistance and signal transduction. Clin Cancer Res 2002;8:885-92.

32 Schlieman MG, Fahy BN, Ramsamooj R, et al. Incidence, mechanism and prognostic value of activated AKT in pancreatic cancer. Br J Cancer 2003:89:2110-15

33 Takes RP, Baatenburg De Jong RJ, Alles MJ, et al. Markers for nodal metastasis in head and neck squamous cell cancer. Arch Otolaryngol Head Neck Surg 2002;128:512-18.

34 Tanaka N, Odajima T, Ogi K, et al. Expression of E-cadherin, alpha-catenin, and beta-catenin in the process of lymph node metastasis in oral squamous cell carcinoma. Br J Cancer 2003;89:557-63. 